\begin{tabular}{|c|c|c|c|}
\hline \multirow{3}{*}{$\begin{array}{r}\text { Case Reports in } \\
\text { Gastroenterology }\end{array}$} & Case Rep Gastroenterol 201 & & \multirow[b]{2}{*}{ Oparger } \\
\hline & $\begin{array}{l}\text { DOI: 10.1159/000450676 } \\
\text { Publisned online: October 18, } 2016\end{array}$ & $\begin{array}{l}\text { (c) } 2016 \text { The Author(s) } \\
\text { Published by S. Karger AG, Basel } \\
\text { www.karger.com/crg }\end{array}$ & \\
\hline & $\begin{array}{l}\text { This article is licensed under the } \\
\text { International License (CC BY-NC) } \\
\text { Usage and distribution for commerci }\end{array}$ & $\begin{array}{l}\text { nons Attribution-NonCommercial } 4 . \\
\text { ger.com/Services/OpenAccessLicense } \\
\text { uires written permission. }\end{array}$ & \\
\hline
\end{tabular}

\title{
Severe Acute Respiratory Distress Syndrome during Infliximab Therapy in a Patient with Crohn Disease
}

\author{
Johanna Schoehl Nicolae-Catalin Mechie Harald Schwoerer \\ Onnen Moerer Michael Quintel Cordula Buck Volker Ellenrieder \\ Albrecht Neesse Ahmad Amanzada \\ Klinik für Gastroenterologie und Gastrointestinale Onkologie, Universitätsmedizin \\ Göttingen, Göttingen, Germany
}

\section{Keywords}

Noninfectious interstitial lung disease $\cdot$ Infliximab $\cdot$ Crohn disease $\cdot$ Acute respiratory distress syndrome

\begin{abstract}
The occurrence of a noninfectious interstitial lung disease is a rare but life-threatening side effect of infliximab, an antitumor necrosis factor alpha antibody. The following case report of a patient with Crohn disease shows an extremely dramatic progression to a severe acute respiratory distress syndrome.

(C) 2016 The Author(s) Published by S. Karger AG, Basel
\end{abstract}

\section{Introduction}

Inflammatory bowel diseases (IBD), which include Crohn disease (CD) and ulcerative colitis (UC), are chronic and disabling diseases with a high and increasing incidence across continents $[1,2]$. With regard to ethnicity, white and Jewish people show the greatest incidence rate of IBD [3].

IBD is characterized by chronic inflammation of the gastrointestinal tract. Factors that contribute towards the pathogenesis of the disease are the host's genetic profile, the immune 
system and environmental factors, such as the gut microbiota [4-6]. Although the etiology of IBD has been extensively studied in the past few decades, the disease pathogenesis is still not fully understood to date.

Universally, the incidence rates for both CD and UC are highest between the second and the fourth decade of life, and gender distribution is equal. Unfortunately, individuals with IBD are affected in the most formidable and productive years of their life, causing a high socioeconomic burden [7].

IBD is characterized by intestinal damage (barrier disruption, microbiota influx) and a high degree of inflammation. Despite similar pathophysiological manifestations on the surface of the intestinal lumen, $\mathrm{CD}$ and $\mathrm{UC}$ are distinct diseases that may require different therapeutic approaches. While CD patients show a transmural inflammation of the bowel wall, UC is restricted to a mucosal and submucosal inflammation $[8,9]$. The development, growth, activation, and function of innate and adaptive immune cells are largely controlled by cytokines. Moreover, an adequate interaction between the gut immune system and gut microbiota is essential. In genetically predisposed individuals, IBD occurs by an excessive production of proinflammatory cytokines, mainly tumor necrosis factor-alpha (TNF- $\alpha$ ) [10].

Over the last 3 decades, IBD therapy has changed with the expanding use of immunosuppressive therapy, i.e., purine antimetabolites and methotrexate as well as the introduction of anti-TNF- $\alpha$ therapy and integrin inhibitors [11, 12]. Ideally, IBD treatment should be individually tailored depending on the inflammatory activity and localization within the digestive tract. In cases with mild inflammatory activity, a therapy with locally active, antiinflammatory compounds, such as mesalazine or budesonide, are mostly sufficient. In cases with moderate-to-severe disease activity, the use of immunosuppressive therapy or biologics is essential [11].

Infliximab, a chimeric monoclonal antibody, inhibits TNF- $\alpha$ and is approved for the treatment of CD, UC, psoriasis, psoriatic arthritis, ankylosing spondylitis, and rheumatoid arthritis [13].

In 1999, the first published phase II study of patients with fistulizing CD treated with infliximab showed that infliximab was effective in closing fistulae between the skin and the bowel in 56-68\% of the patients [14]. Moreover, another large phase III clinical trial showed that infliximab was additionally beneficial in maintaining the closure of fistulae in almost two-thirds of all patients. This final trial resulted in the FDA approval of the drug to treat fistulizing CD [15]. Therefore, infliximab is a standard therapy for CD patients with moderate or severe inflammatory activity. To date, numerous reports about side effects of infliximab in various inflammatory disorders have been published [16]. Here, we report a rare case of a male patient with CD who suffered from a severe acute respiratory distress syndrome following infliximab administration.

\section{Clinical Course}

A 62-year-old male was diagnosed with CD of the colon with extra intestinal skin manifestation (pyoderma gangrenosum) in April 2015 and was treated with systemic steroids. The medical history revealed arterial hypertension, atrial fibrillation, coronary heart disease, and peripheral artery occlusive disease stage III of the right thigh. Furthermore, the patient reported heavy past nicotine use (35 pack years).

Due to steroid-refractory disease, infliximab was started with an induction regimen (weeks 0,2 , and 6) followed by maintenance in July/August 2015. Prior to the anti-TNF- $\alpha$ 
therapy, there was no evidence of hepatitis A, B, C, E (negative serology), HIV (negative serology), or tuberculosis (QuantiFERON-TB test). The chest X-ray revealed minimal pleural effusion before initiation of the therapy (fig. 1a). Cough and exertional dyspnea appeared after the third infusion of infliximab. Due to these symptoms of a respiratory tract infection, the fourth administration of infliximab was suspended in September, and antibiotics were administered. Under antibiotic therapy with amoxicillin/clavulanic acid, the patient showed no improvement of the clinical symptoms.

In October 2015, the patient was admitted to our ward with progressive dyspnea. At hospital admission, the leucocytes were $5.61 \times 10^{3} / \mu \mathrm{l}$ (normal range $4.0-11.0 \times 10^{3} / \mu \mathrm{l}$ ), but C-reactive protein was elevated to $49.4 \mathrm{mg} / \mathrm{l}$ (reference $\leq 5.0$ ). Auscultation showed a crackle on both sides. We escalated the antibiotic therapy to moxifloxacin and clarithromycin. The urine and blood bacterial cultures were negative. In the blood serology, there was no evidence of Aspergillus, Candida, Cryptococcus, Chlamydia pneumoniae, Chlamydia psittaci, Legionella, Mycoplasma pneumoniae, Coxiella burneti or Aspergillus. The functional respiratory tests showed a restriction and a severe diffusion disorder (fig. 2). The bronchoscopy showed signs of a chronic bronchitis, and there was no evidence of malignity. The follow-up chest X-ray showed reticular signs on both sides (fig. 1b). Computed tomography (CT) imaging demonstrated pronounced reticular and fibrotic changes within the lung parenchyma suggestive of idiopathic lung fibrosis (fig. 1c).

Therefore, we started a steroid therapy, initially $100 \mathrm{mg}$ prednisolone orally. Nevertheless, the lung function of the patient deteriorated rapidly. Because of hypoxemia with an arterial oxygen partial pressure of $24 \mathrm{~mm} \mathrm{Hg}$ (reference 65-105) in the blood gas analysis, we transferred the patient to the intensive care unit for noninvasive ventilation. Over the course of time, the respiratory condition aggravated further. Neither the noninvasive ventilation nor high-flow oxygen therapy (AirVo ${ }^{\circledR}$-System) were able to achieve sufficient oxygenation. Microbiological tests revealed Haemophilus parainfluenzae in the sputum, and broad antibiotic therapy was administered despite the lack of obvious infectious clues (normal values for leukocytosis and procalcitonin). Under antibiotic treatment, we escalated the immune suppression with intravenous methylprednisolone $1 \mathrm{~g}$ for 3 days and subsequently continued with $100 \mathrm{mg}$ prednisolone daily to treat the lung fibrosis. Based on our interdisciplinary board decision, we implanted an extracorporeal membrane oxygenation (ECMO) and administered a second round of high-dose intravenous methylprednisolone $1 \mathrm{~g}$ for 3 days. Initially, the gas exchange with ECMO did not improve promptly, but from day 6 until after implantation, the respiration improved slowly. Lung transplantation was rejected by two independent transplantation centers. ECMO was continued for more than 6 weeks, and the prednisolone therapy was tapered to $25 \mathrm{mg}$ daily. The patient was awake during all times and not intubated or mechanically ventilated. Weaning with intermittent noninvasive ventilation and oxygen was finally successful, and the patient could leave the intensive care unit with 4-6 liter/min of oxygen.

One month later, the patient was discharged with 2 liter/min of oxygen. The CT scan before discharge from hospital showed residual inflammatory signs and persistent pulmonary fibrosis. Based on the close temporal association between the start of infliximab therapy and the onset of respiratory symptoms, we believe that the pulmonary fibrosis was caused by the immunosuppressive treatment. 


\section{Discussion}

Pulmonary complications of infliximab have been known for several years in patients with rheumatoid arthritis [17]. Due to the temporal association, it must be assumed that infliximab induced the alveolitis/pulmonary fibrosis. In our patient, respiratory symptoms were observed after the third infusion of infliximab. The same onset of respiratory symptoms was also described in a rheumatology case [17]. Riegert-Johnson et al. [18] described a delayed hypersensitivity reaction and acute respiratory distress syndrome following the second infliximab infusion. The previous existence of lung disease in our patient cannot be excluded. Notably, he was a smoker, and the chest X-ray showed minimal pleural effusion prior to therapy initiation. However, a functional respiratory test was not performed before the initiation of infliximab therapy, since the patient did not report any symptoms. The study of Curtis et al. [19] found that older patients, men, and patients with a history of other pulmonary disorders or recent exposure to glucocorticoids using tocolizumab, rituximab, abatacept, or anti-TNF- $\alpha$ agents were at increased risk for developing interstitial lung disease. The mechanisms of interstitial lung disease exacerbation after initiation of TNF- $\alpha$ inhibitors are considered to be caused by the interaction of cytokine release upon these agents [20].

\section{Conclusion}

In case of pulmonary risk factors, infliximab should be applied with great care and should be explicitly mentioned on the patient informed consent form. Moreover, regular monitoring of patients in specialized outpatient clinics is mandatory to detect such lifethreatening but rare side effects early.

\section{Acknowledgments}

This paper was supported by the German Research Foundation and the Open Access Publication Funds of the University of Göttingen.

\section{Statement of Ethics}

Written consent of the patient has been obtained.

\section{Disclosure Statement}

The authors declare that there are no conflicts of interest to disclose. 


\section{Case Reports in \\ Gastroenterology}

Case Rep Gastroenterol 2016;10:574-580

DOI: $10.1159 / 000450676$

C 2016 The Author(s). Published by S. Karger AG, Basel www.karger.com/crg

Schoehl et al: Severe Acute Respiratory Distress Syndrome during Infliximab Therapy in a Patient with Crohn Disease

\section{References}

1 Loftus E: Clinical epidemiology of inflammatory bowel disease: incidence, prevalence, and environmental influences. Gastroenterology 2004;126:1504-1517.

2 Molodecky NA, et al: Increasing incidence and prevalence of the inflammatory bowel diseases with time, based on systematic review. Gastroenterology 2012;142:46-54.

-3 Hou JK, El-Serag H, Thirumurthi S: Distribution and manifestations of inflammatory bowel disease in Asians, Hispanics, and African Americans: a systematic review. Am J Gastroenterol 2009;104:21002109.

4 Mikhailov TA, Furner SE: Breastfeeding and genetic factors in the etiology of inflammatory bowel disease in children. World J Gastroenterol 2009;15:270-279.

-5 Danese S, Sans M, Fiocchi C: Inflammatory bowel disease: the role of environmental factors. Autoimmun Rev 2004;3:394-400.

Podolsky DK: Inflammatory bowel disease. N Engl J Med 2002;347:417-429.

7 Yu AP, Cabanilla LA, Wu EQ, et al: The costs of Crohn"s disease in the United States and other Western countries: a systematic review. Curr Med Res Opin 2008;24:319-328.

8 Baumgart DC, Sandborn WJ: Crohn's disease. Lancet 2012;380:1590-1605

9 Danese S, Fiocchi C: Ulcerative colitis. N Engl J Med.2011;365:1713-1725.

10 Liu ZG: Molecular mechanism of TNF signaling and beyond. Cell Res 2005;15:24-27.

-11 Dignass A, Van Assche G, Lindsay JO, et al: The second European evidence-based consensus on the diagnosis and management of Crohn's disease: current management. J Crohns Colitis 2010;4:28-62.

12 Amiot A, Peyrin-Biroulet L: Current, new and future biological agents on the horizon for the treatment of inflammatory bowel diseases. Ther Adv Gastroenterol 2015;8:66-82.

13 European Medicines Agency: Remicade (infliximab). http://www.ema.europa.eu/ema/index.jsp?curl=pages/medicines/human/medicines/000240/human _med_001023.jsp\&mid=WC0b01ac058001d124.

14 Present DH, Rutgeerts P, Targan S, Hanauer SB, Mayer L, van Hogezand RA, Podolsky DK, Sands BE, Braakman T, DeWoody KL, Schaible TF, van Deventer SJ: Infliximab for the treatment of fistulas in patients with Crohn's disease. N Engl J Med 1999;340:1398-1405.

15 Ands BE, Anderson FH, Bernstein CN, Chey WY, Feagan BG, Fedorak RN, Kamm MA, Korzenik JR, Lashner BA, Onken JE, Rachmilewitz D, Rutgeerts P, Wild G, Wolf DC, Marsters PA, Travers SB, Blank MA, van Deventer SJ: Infliximab maintenance therapy for fistulizing Crohn's disease. N Engl J Med 2004;350:876-885.

-16 Neesse A, Michl P, Kunsch S, Ellenrieder V, Gress TM, Steinkamp M: Simultaneous onset of ulcerative colitis and disseminated pyoderma gangrenosum. Case Rep Gastroenterol 2007;1:110-115.

-17 Ostör AJ, Chilvers ER, Somerville MF, Lim AY, Lane SE, Crisp AJ, Scott DG: Pulmonary complications of infliximab therapy in patients with rheumatoid arthritis. J Rheumatol 2006;33:622-628.

-18 Riegert-Johnson DL, Godfrey JA, Myers JL, Hubmayr RD, Sandborn WJ, Loftus EV Jr: Delayed hypersensitivity reaction and acute respiratory distress syndrome following infliximab infusion. Inflamm Bowel Dis 2002;8:186-191.

19 Curtis JR, Sarsour K, Napalkov P, Costa LA, Schulman KL: Incidence and complications of interstitial lung disease in users of tocilizumab, rituximab, abatacept and anti-tumor necrosis factor $\alpha$ agents, a retrospective cohort study. Arthritis Res Ther 2015;17:319.

-20 Nakashita T, Ando K, Kaneko N, Takahashi K, Motojima S: Potential risk of TNF inhibitors on the progression of interstitial lung disease in patients with rheumatoid arthritis. BMJ Open 2014;4:e005615 


\section{Case Reports in Gastroenterology}

\begin{tabular}{l|l}
\hline Case Rep Gastroenterol 2016;10:574-580 \\
\hline DOI: 10.1159/000450676 & $\begin{array}{l}\text { C 2016 The Author(s). Published by S. Karger AG, Basel } \\
\text { www.karger.com/crg }\end{array}$ \\
\hline
\end{tabular}
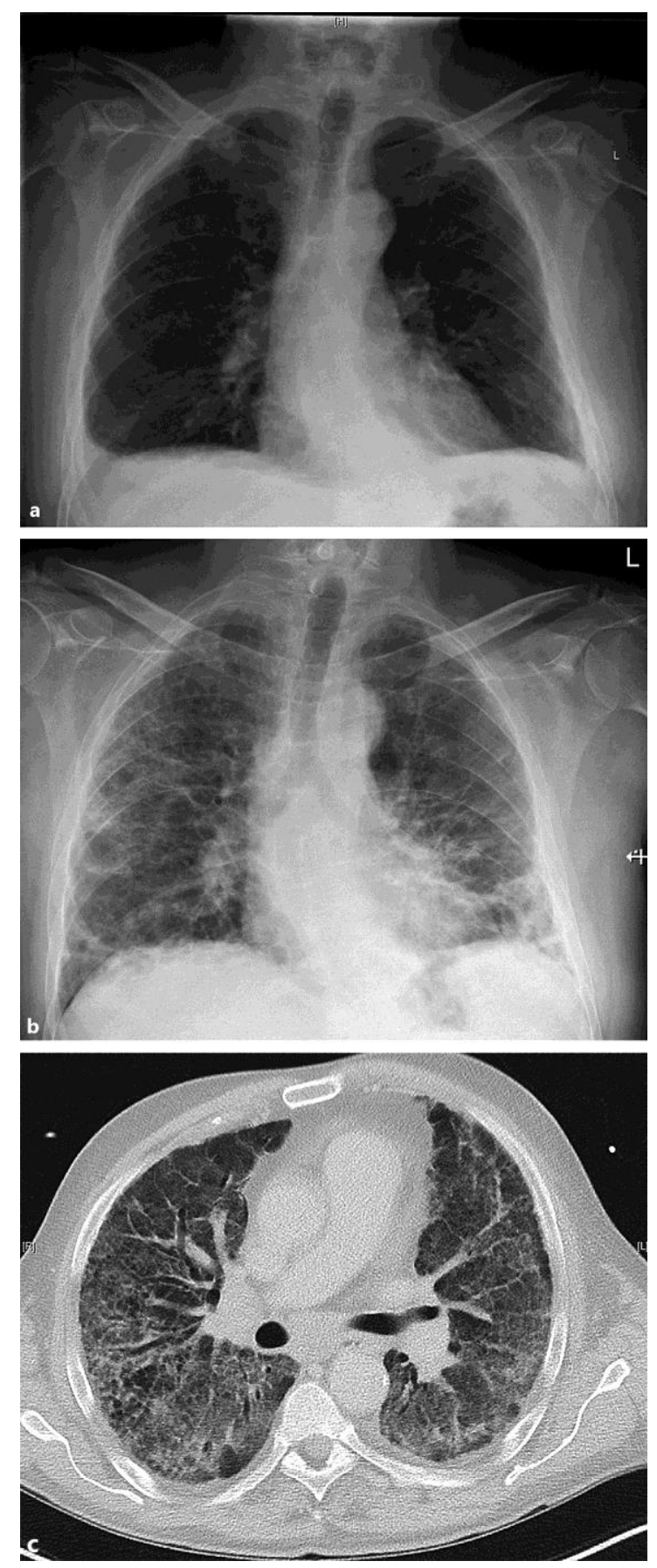

Fig. 1. a In the chest X-ray before initiation of the therapy, minimal pleural effusions are visible. $\mathbf{b}$ The follow-up chest X-ray shows reticular signs on both sides. c Pronounced reticular and fibrotic changes within the lung parenchyma suggestive of idiopathic lung fibrosis. 

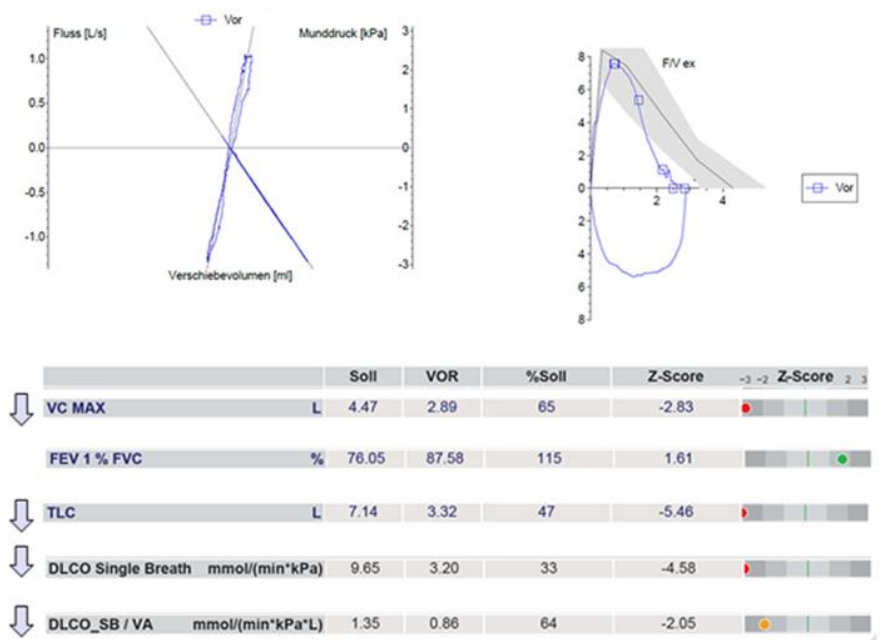

Fig. 2. Functional respiratory test. The diminished vital capacity (VC) and total lung capacity (TLC) but normal Tiffeneau index (FEV 1\% FVC) indicate a restriction. The diminished diffusion capacity for CO (DLCO) of the single breath (33\%) shows a severe diffusion disorder. 